\title{
Phylogenetic history of plastid-targeted proteins in the peridinin-containing dinoflagellate Heterocapsa triquetra
}

\author{
Ross F. Waller,† Nicola J. Patron and Patrick J. Keeling \\ Canadian Institute for Advanced Research, Department of Botany, University of British \\ Columbia, 3529-6270 University Boulevard, Vancouver, BC, V6T 1Z4, Canada
}

Correspondence
Patrick J. Keeling
pkeeling@interchange.ubc.ca

\section{INTRODUCTION}

Plastids originated by the endosymbiotic uptake of a cyanobacterium and the subsequent conversion of this endosymbiont into the highly reduced and specialized double-membrane-bound primary plastid found today in land plants and some algae. Most algal groups, however, acquired their plastids by an additional step called secondary endosymbiosis. Here, an alga containing a primary plastid is itself taken up and converted into an organelle within its new eukaryotic host (Archibald \& Keeling, 2002). These secondary plastids are bounded by either three or four membranes and are found in chlorarachniophytes, euglenids, cryptomonads, heterokonts, haptophytes, dinoflagellates and apicomplexans. In all of these groups, the plastid retains only a small genome: most proteins are nuclearencoded and are targeted post-translationally to the plastid

tPresent address: Botany School, University of Melbourne, Parkville, VIC 3010, Australia.

Abbreviations: EST, expressed sequence tag; FBA, fructose-1,6bisphosphate aldolase; GAPDH, glyceraldehyde-3-phosphate dehydrogenase.

The GenBank/EMBL/DDBJ accession numbers for the completed cDNA sequences reported in this study are AY826826-AY826947 and AY884246-AY884255. The dbEST accession numbers for the EST sequences reported in this study are DT379484-DT386290.

Protein maximum-likelihood trees for a further 23 plastid-targeted proteins are available as supplementary material in IJSEM Online. using specific $\mathrm{N}$-terminal peptides that are characteristic for either primary or secondary plastids (McFadden, 2001).

Dinoflagellates are closely related to apicomplexans and, together with ciliates and a handful of other protists, make up the alveolates (Fast et al., 2002; Gajadhar et al., 1991). Since many members of both dinoflagellates and apicomplexans contain secondary plastids, the most parsimonious explanation is that they share a common origin, but the evolutionary history of both plastids has proved contentious, in part because they are divergent, making them difficult to compare.

While some dinoflagellates have undergone plastid replacements through further endosymbiotic events (Delwiche, 1999; Keeling, 2004), the plastid found in the majority of photosynthetic dinoflagellates is a secondary plastid containing the distinctive pigment peridinin. This plastid is further distinguished in many ways, not least in that it has three membranes rather than four, which appears to have a significant affect on how proteins are targeted to the organelle (Nassoury et al., 2003; Patron et al., 2005). The genomes of dinoflagellate plastids are also the most reduced known. All but a few of their genes have moved to the nucleus (Bachvaroff et al., 2004; Hackett et al., 2004a), and the remaining genome ( 16 genes have been found so far, nearly all related to photosynthesis) has been broken up into mini-circles each generally encoding a single gene (Zhang et al., 1999). 
Apicomplexans, on the other hand, are obligate parasites, so their plastid (the apicoplast) is non-photosynthetic and generally reduced. Its relict genome contains few genes, typically highly divergent at the sequence level, and mostly encoding housekeeping functions (Wilson et al., 1996). The evolutionary origin of this plastid has been debated since its discovery, with some data interpreted as showing a green algal origin (Cai et al., 2003; Funes et al., 2002; Köhler et al., 1997) and other data interpreted as showing a red algal origin (Blanchard \& Hicks, 1999; Fast et al., 2001; McFadden \& Waller, 1997; Patron et al., 2004; Waller et al., 2003). Since nearly all of the genes remaining in the dinoflagellate plastid are related to photosynthesis, there are few plastid-encoded genes that can be compared directly between apicomplexans and dinoflagellates. Those that have been (primarily encoding small- and large-subunit rRNA) are highly divergent in both groups, making phylogenies difficult to interpret (Zhang et al., 2000).

The disputes over the origin of dinoflagellate and apicomplexan plastids widened with the suggestion that both plastids originated in the ancestor of all chromalveolates. The chromalveolates are a hypothetical grouping of alveolates and chromists (cryptomonads, haptophytes and heterokonts): all eukaryotes hypothesized to have red algal-derived plastids (Cavalier-Smith, 1998). Plastid-encoded gene trees have given variable results, but multigene analyses weakly unite chromist plastids (Yoon et al., 2002, 2004). Nuclear gene trees provide strong support for the alveolates and their relationship to heterokonts (Baldauf et al., 2000; Harper et al., 2005). Taken together, plastid and cytosolic data are therefore consistent with the chromalveolate hypothesis, but neither support the whole group: the strongest support for this comes from two nucleus-encoded genes for plastidtargeted proteins: glyceraldehyde-3-phosphate dehydrogenase (GAPDH) and fructose-1,6-bisphosphate aldolase (FBA) (Fast et al., 2001; Harper \& Keeling, 2003; Patron et al., 2004). In both cases, the chromalveolate plastidtargeted protein appears to have evolved in a unique way relative to other plastids, and these deviations suggest that plastids of chromalveolates share a common origin.

Phylogenies of GAPDH and FBA demonstrate the usefulness of nucleus-encoded plastid-targeted proteins for studying plastid evolution, but they are poorly sampled because the nuclear genome is practically less accessible than that of the plastid. In dinoflagellates, this problem is aggravated by their unusually large genome size, so expressed sequence tag (EST) surveys have been used to generate genomic data from several species of dinoflagellate (Bachvaroff et al., 2004; Hackett et al., 2004a; Patron et al., 2005). Phylogenetic analyses for some of these proteins have been carried out, some showing a substantial conflict in gene trees indicating either a red or green algal origin, or high levels of lateral gene transfer (Hackett et al., 2004a). Here, we have phylogenetically analysed all the plastid-targeted proteins identified from an EST survey of the dinoflagellate Heterocapsa triquetra (Patron et al., 2005). We have inferred phylogenies for 52 proteins, eight of which have apicomplexan homologues. Overall, the dinoflagellate plastid proteins tend to branch with red algae and chromists (with red algal secondary plastids) with stronger consistency than previously observed. Of the phylogenies containing apicomplexan homologues that are resolved with reasonable support, the apicomplexans group within the red algal plastid clade and a specific relationship with the dinoflagellate homologues was evident in some of these. Many dinoflagellate plastidtargeted proteins are relatively divergent and contain unique oddities [such as a tandem fusion of translation elongation factor Ts (EF-Ts)], and a few well-resolved phylogenies appear to support lateral gene transfer, including genes derived from prokaryotes.

\section{METHODS}

EST sequencing and protein identification. $H$. triquetra CCMP 449 , cultivated in Guillard's f2-Si medium at $16^{\circ} \mathrm{C}$ with a $12 \mathrm{~h}: 12 \mathrm{~h}$ light/dark cycle, was harvested in batches and total RNA was used to construct a cDNA library as described by Patron et al. (2005). ESTs were $5^{\prime}$-sequenced and gene identification was performed at the PEPdb (http://amoebidia.bcm.umontreal.ca/pepdb/searches/welcome. php). Plastid-targeted proteins were identified as part of an analysis of the nature of plastid-targeting leader sequences in dinoflagellates reported in Patron et al. (2005). Briefly, EST annotation was searched for genes with known function in the plastid and the sequence database was searched using known plastid-targeted proteins from other organisms. In cases where candidate genes were determined to be full-length, they were analysed for the presence of an N-terminal leader with characteristics expected of a dinoflagellate plastid-targeting peptide (in particular the presence of a predicted signal peptide). In addition, phylogenetic analysis was carried out for all candidate genes (see below), revealing some to be related to cytosolic or mitochondrial homologues. In these cases, unless the gene encoded a leader warranting further investigation, they were no longer considered. In cases where cDNAs were truncated and the presence of a leader could not be verified, genes were considered to encode plastid-targeted proteins if they were phylogenetically related to other plastid-targeted homologues and to cyanobacterial homologues. Identification of putatively plastid-targeted proteins in apicomplexans followed previous annotation, which is based on the well-characterized leaders of annotated proteins (Ralph et al., 2004) and direct localization (e.g. Jomaa et al., 1999; Waller et al., 1998). Completed cDNA sequences have been deposited in GenBank (accession numbers AY826826-AY826947, AY884246-AY884255) and EST sequences have been deposited in dbEST (DT379484DT386290).

Phylogenetic analysis. Protein alignments were constructed using CLUSTAL X (Thompson et al., 1997) and edited manually. All ambiguous sites of the alignments were removed from the dataset for phylogenetic analyses. The alignment data are available on request. Protein maximum-likelihood analyses used PhyML (Guindon \& Gascuel, 2003) with input trees generated by BIONJ, the JTT model of amino acids substitution, proportion of variable rates estimated from the data and nine categories of substitution rates (eight variable and one invariable). One hundred bootstrap trees were calculated with PhyML initially without gamma correction categories; if the resulting trees showed resolution, the analysis was repeated with four rate categories. For distance analyses, gamma-corrected distances were calculated by TREE-PUZZLE 5.2 (Schmidt et al., 2002) using the WAG substitution matrix with eight variable rate categories and invariable sites. Trees were inferred by weighted 
neighbour-joining using WEIGHBOR 1.0.1a (Bruno et al., 2000). Bootstrap resampling was performed using PUZZLEBOOT (shell script by A. Roger and M. Holder; http://www.tree-puzzle.de) with rates and frequencies estimated using TREE-PUZZLE 5.2.

\section{RESULTS AND DISCUSSION}

\section{Red algal origin of Heterocapsa plastid- targeted proteins}

A previous analysis of plastid-targeting leaders in $\mathrm{H}$. triquetra (Patron et al., 2005) identified a total of 63 distinct genes from 2022 EST clusters as likely being plastid-targeted protein-coding genes. Of these, 11 represented multiple copies of certain genes; hence there were 52 distinct plastid proteins identified in total (including several distinct lineages within the light-harvesting complex superfamily). The majority of these proteins are involved in the light or dark reactions of photosynthesis, but other activities such as transcription, translation or synthesis of fatty acids and isoprenoids were also represented, and eight proteins representing such functions had identifiable homologues in apicomplexans. These plastid proteins were each subjected to phylogenetic analyses, with the exceptions of form II ribulose-1,5-bisphosphate carboxylase oxygenase $(\mathrm{RuBis} \mathrm{CO})$, which has already been analysed in detail and is known to be unique to dinoflagellates and photosynthetic proteobacteria (Whitney et al., 1995), and the lightharvesting complex proteins, which we found to form a poorly resolved protein family in dinoflagellates. Furthermore, dinoflagellate GAPDH, FBA and PsbO have been analysed previously (Fast et al., 2001; Harper \& Keeling, 2003; Ishida \& Green, 2002; Patron et al., 2004).

Of the 34 discrete proteins analysed (Table 1), many of the $H$. triquetra genes were divergent compared with other plastid homologues, and the position of $H$. triquetra was completely unresolved in two cases. The other 32 proteins supported $H$. triquetra branching with other plastid homologues, as expected. Of these, $H$. triquetra branched with neither the red nor green algal lineages (i.e. the position was unresolved within plastids) or, in 18 cases, plastids were polyphyletic. H. triquetra branched with the red plastid lineage (red and chromistan algae) in another 13 cases, eight with moderate to strong support, as shown in three examples in Fig. 1. In the phosphoglycerate kinase phylogeny (Fig. 1a), the H. triquetra genes for the plastid and cytosolic enzymes are both shown, and the plastid gene branches within a relatively well supported ( $89 \%)$ clade of red algal and chromists genes, as well as Bigelowiella natans, which has a green algal secondary plastid and whose phosphoglycerate kinase has been proposed to be derived from a red alga by lateral gene transfer (Archibald et al., 2003). Similarly, H. triquetra phosphoribulokinase (Fig. 1b) branches specifically with chromist homologues, and most closely with the haptophyte Isochrysis (94-96\%). Lastly, $H$. triquetra and Alexandrium tamarense (Hackett et al., 2004a) possess a gene for photosystem II extrinsic protein (Fig. 1c), a protein apparently lost from green algae altogether and otherwise only known in cyanobacteria, red algal plastids and their chromist derivatives.

As a whole, the phylogenies of $H$. triquetra plastid-targeted proteins are most consistent with the peridinin-containing plastid being derived from a red algal plastid. This is in line with results from plastid-encoded genes (Zhang et al., 2000) and a few plastid-targeted genes (Bachvaroff et al., 2004; Hackett et al., 2004a). However, in some analyses, several proteins have shown a green algal origin (Hackett et al., 2004a) and, in one multigene analysis, the red origin was not significantly better supported than a green algal origin (Yoon et al., 2005). We see no strong evidence for a green algal origin and only a few cases that might suggest lateral gene transfer (see below). In nearly all resolved cases, $H$. triquetra branches specifically with heterokonts, haptophytes or cryptomonads, while only three proteins show $H$. triquetra branching with a red alga to the exclusion of these taxa; none of these are statistically supported. Among the more strongly supported phylogenies, the data are more consistent with the chromalveolate hypothesis than with independent plastid origins; however, broader representation of red algal taxa is required in order to test this hypothesis more thoroughly.

\section{Relationship between dinoflagellate and apicomplexan plastid-targeted proteins}

Most of the $H$. triquetra plastid-targeted proteins are involved in photosynthesis and so are not present in apicomplexans. However, eight proteins were identified from both groups (see asterisks in Table 1), and the phylogenies of four offer some resolution (Fig. 2). The phylogenies of both dimethyladenosine synthase (Fig. 2a) and queuine tRNA ribosyltransferase (Fig. $2 \mathrm{~b}$ ) support dinoflagellates and apicomplexans as sister taxa within the red plastid clade. The latter is also of interest because it is not known from green plastids. Interestingly, however, the dinoflagellateapicomplexan clade of queuine tRNA ribosyltransferase also includes two alphaproteobacterial sequences, the chromist plastid sequences and a Dictyostelium homologue, and there is no clear relationship between plastid genes in general and cyanobacterial homologues. Ultimately, the source of this protein in plastids is unclear: it is possible the proteobacteria and Dictyostelium each acquired this gene from plastids, but it is also possible the plastid genes are not ancestrally cyanobacterial or that there are many paralogues. In any case, the $H$. triquetra gene forms a strongly supported group with Toxoplasma (91-99\%), suggesting that they are mostly likely closely related, and the presence of this protein in apicomplexans is not consistent with their having a plastid of green algal ancestry. 1-Deoxy-D-xylulose5-phosphate synthase (Fig. 2c) also places apicomplexans firmly within the red plastid clade, although the position of $H$. triquetra is unresolved within this red group. Apicomplexans are, nevertheless, moderately strongly allied to the chromist Thalassiosira (74-82\%) and not the green plastid lineage. 
Table 1. H. triquetra plastid-targeted proteins predicted from cDNAs sorted by inferred evolutionary origin

The phylogenetic position of $H$. triquetra protein sequences is indicated where $H$. triquetra groups within either a clade of red algal and red algal-derived plastids (Red) or green algal and green algal-derived plastids (Green). If the H. triquetra position is not resolved with either of these groups but still groups within the plastid clade, this is indicated by 'Plastid'. The level of support from maximum-likelihood and weighted neighbour-joining bootstrap for these groups is indicated as follows: +++ , greater than $80 ;++, 70-80$;,$+ 60-70$; no symbol, below 60. Proteins for which homologues are represented in apicomplexans are indicated by asterisks.

\begin{tabular}{|c|c|c|c|}
\hline Protein (gene) & GenBank accession no. & Phylogeny & Figure/reference \\
\hline \multicolumn{4}{|l|}{ Red algal/chromalveolate } \\
\hline Phosphoglycerate kinase ( $p g k$ ) & AY826862 & $\operatorname{Red}+++$ & Fig. 1a \\
\hline Phosphoribulokinase (prk) & AY826860 & Red +++ & Fig. $1 b$ \\
\hline Photosystem II extrinsic protein ( $p s b U$ ) & AY826889 & Red +++ (no green $)$ & Fig. 1c \\
\hline Dimethyladenosine synthase $^{\star}(k s g A)$ & AY826874 & Red & Fig. 2a \\
\hline Queuine tRNA ribosyltransferase* $(\operatorname{tg} t)$ & AY826892 & Red +++ & Fig. $2 b$ \\
\hline 1-Deoxy-D-xylulose-5-phosphate synthase $(d x s)$ & AY826876 & Red & Fig. $2 \mathrm{c}$ \\
\hline Ribose-5-phosphate isomerase (rpiA) & AY826893 & Red +++ & Supplementary Fig. S1 \\
\hline Cytochrome $f($ pet $A)$ & AY826881 & Red & Supplementary Fig. S2 \\
\hline Cytochrome 6559 ( $p s b F)$ & AY826887 & Red (plus B. natans) & Supplementary Fig. S3 \\
\hline Transketolase $(t k t A)$ & AY826896 & Red & Supplementary Fig. S4 \\
\hline $\mathrm{GAPDH}^{*}$ & AY884246, AY884247 & $\operatorname{Red}+++$ & Takishita et al. (2005) \\
\hline Fructose-1,6-bisphosphate aldolase $(f b a A)$ & AAV71135 & $\operatorname{Red}+++$ & Patron et al. (2004) \\
\hline Oxygen-evolving enhancer 1 ( $p s b O)$ & AAM77465 & $\operatorname{Red}+++$ & Ishida \& Green (2002) \\
\hline \multicolumn{4}{|l|}{ Green algal/plant } \\
\hline Oxoglutarate/malate translocator & AY826859 & Green $+++($ no red $)$ & Fig. 3a \\
\hline Protochlorophyllide reductase subunit (chlL) & AY826880 & Green & Supplementary Fig. S5 \\
\hline Photosystem I subunit III ( $p s a F)$ & AY826884 & Green & Supplementary Fig. S6 \\
\hline \multicolumn{4}{|l|}{ Non-plastid } \\
\hline Acetolactate synthase (als) & AY826826 & Bacteria +++ & Fig. $3 b$ \\
\hline RuBisCO form II & AY826897 & Bacteria +++ & Whitney et al. (1995) \\
\hline \multicolumn{4}{|l|}{ Red/green unresolved } \\
\hline Photosystem II protein L ( $p s b L)$ & AY826888 & Plastid & Supplementary Fig. S7 \\
\hline Thylakoid $11 \mathrm{kDa}$ protein & AY826895 & Plastid & Supplementary Fig. S8 \\
\hline Translation elongation factor Ts ( $t s f)$ & AY826878 & Plastid & Fig. $3 c$ \\
\hline Ferredoxin ${ }^{\star}($ petF $)$ & AY826847, AY826848 & Plastid & Supplementary Fig. S9 \\
\hline Ferredoxin-NADP ${ }^{+}$reductase $^{*}($ pet $H)$ & AY826853 & Plastid & Supplementary Fig. S10 \\
\hline Geranylgeranyl reductase/hydrogenase & AY826855 & Plastid & Supplementary Fig. S11 \\
\hline Beta-keto-acyl reductase & AY826869 & Plastid & Supplementary Fig. S12 \\
\hline Carbonic anhydrase (yadF) & AY826838-AY826840 & Plastid & Supplementary Fig. S13 \\
\hline ATP synthase subunit gamma $(\operatorname{atp} C)$ & AY826835 & Plastid & Supplementary Fig. S14 \\
\hline ATP synthase subunit $\mathrm{C}($ atpH$)$ & $\begin{array}{l}\text { AY826871, AY884249- } \\
\text { AY884255 }\end{array}$ & Plastid & Supplementary Fig. S15 \\
\hline Cytochrome b6 (petC) & AY826843 & Plastid & Supplementary Fig. S16 \\
\hline Cytochrome c6 (petJ) & AY826872, AY884248 & Plastid & Supplementary Fig. S17 \\
\hline Photosystem I protein E ( $p s a E)$ & AY826882 & Plastid & Supplementary Fig. S18 \\
\hline Ascorbate peroxidase & AY826833 & Plastid & Supplementary Fig. S19 \\
\hline Adenylate kinase (adk) & AY826832 & Plastid & Supplementary Fig. S20 \\
\hline Photosystem I subunit XI ( $p s a L)$ & AY826885 & Plastid & Supplementary Fig. S21 \\
\hline Acyl carrier protein* $(a c p)$ & AY826829 & Plastid and mitochondrion & Supplementary Fig. S22 \\
\hline Lipoate protein ligase ${ }^{\star}$ & AY826879 & Plastid and mitochondrion & Supplementary Fig. S23 \\
\hline
\end{tabular}

GAPDH provides further support for dinoflagellates and apicomplexans grouping in the chromalveolates, although not as sisters. This gene has been analysed in detail previously (Fast et al., 2001; Harper \& Keeling, 2003; Takishita et al., 2005) and will therefore not be described here except to state that the $H$. triquetra data are consistent with previous observations that GAPDH supports the origin of both dinoflagellate and apicomplexan plastids from the red plastid clade and that the apicomplexan homologues are specifically related to those of haptophytes, not 
(a) Phosphoglycerate kinase

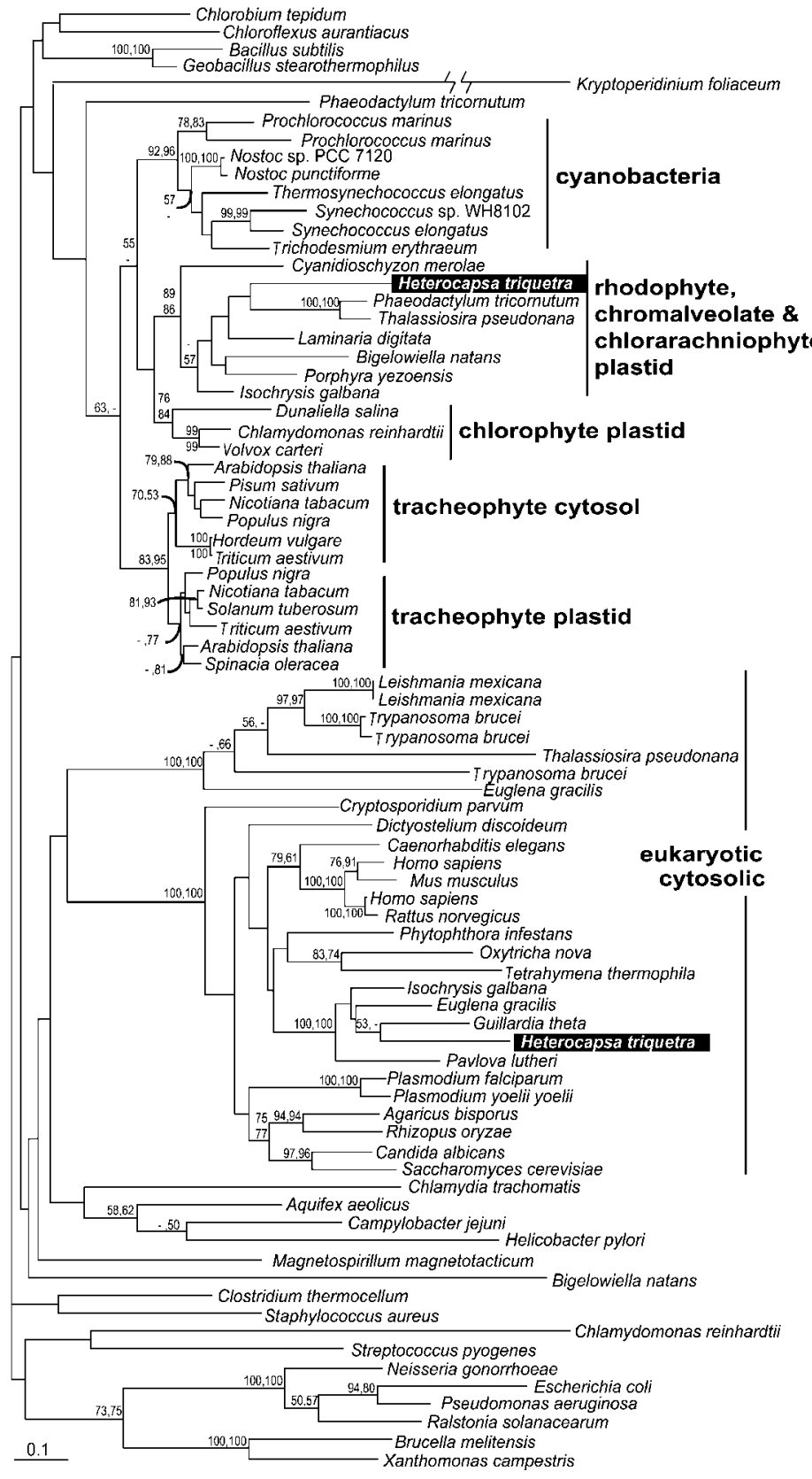

(b) Phosphoribulokinase

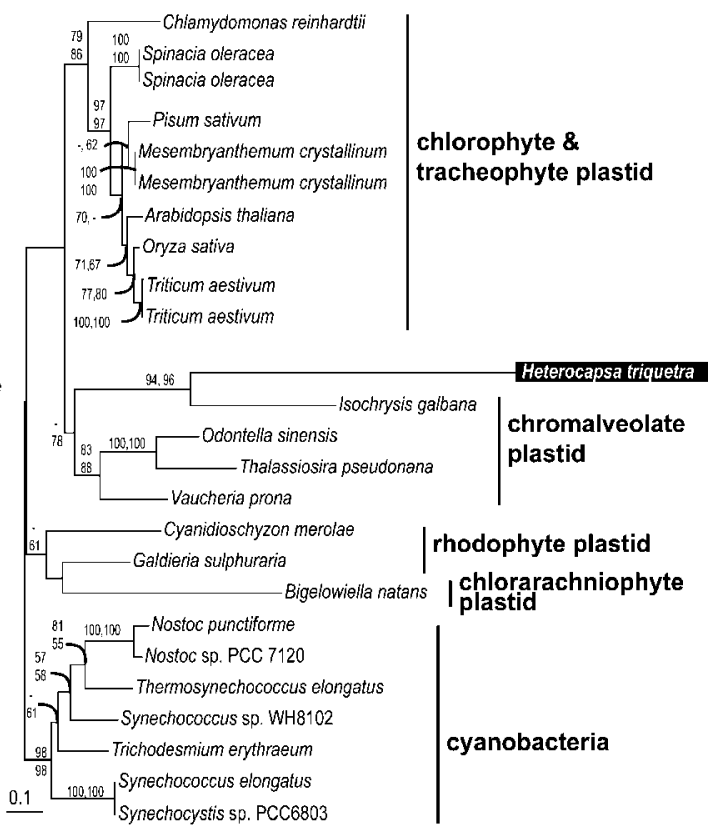

(c) Photosystem II extrinsic protein

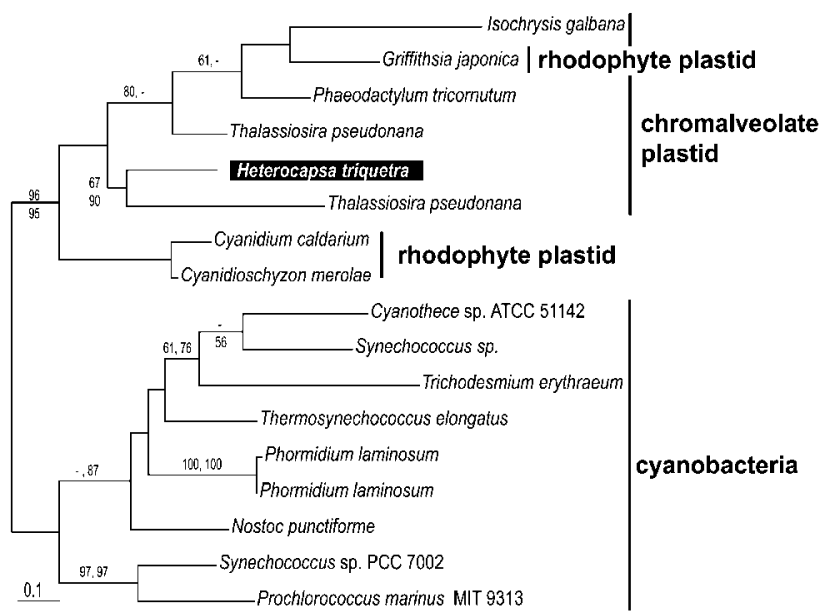

Fig. 1. Relationship of dinoflagellate plastid-targeted proteins phosphoglycerate kinase (a), queuine tRNA ribosyltransferase (b) and photosystem II extrinsic protein (c) to homologues from red algal and chromist plastids. Numbers at nodes indicate bootstrap support (ML top/left; NJ bottom/right) for major nodes over $50 \%$ by at least one method. Major eukaryotic groups and plastids are indicated to the right.

dinoflagellates. Plastid-targeted TufA was originally used to argue for a green algal origin of apicomplexan plastids (in the absence of data from dinoflagellates) (Köhler et al., 1997), but it has now been shown that the apicomplexan and dinoflagellate homologues are closely related (Hackett et al., 2004a), in our view ruling this gene out as support for a green plastid in apicomplexans.

\section{Evidence for lateral gene transfer and gene fusions in dinoflagellate plastid-targeted proteins}

Previously it has been shown that $B$. natans, a chlorarachniophyte alga with a green algal secondary plastid, acquired several plastid-targeted protein genes from other 
(a) Dimethyl adenosine sythase

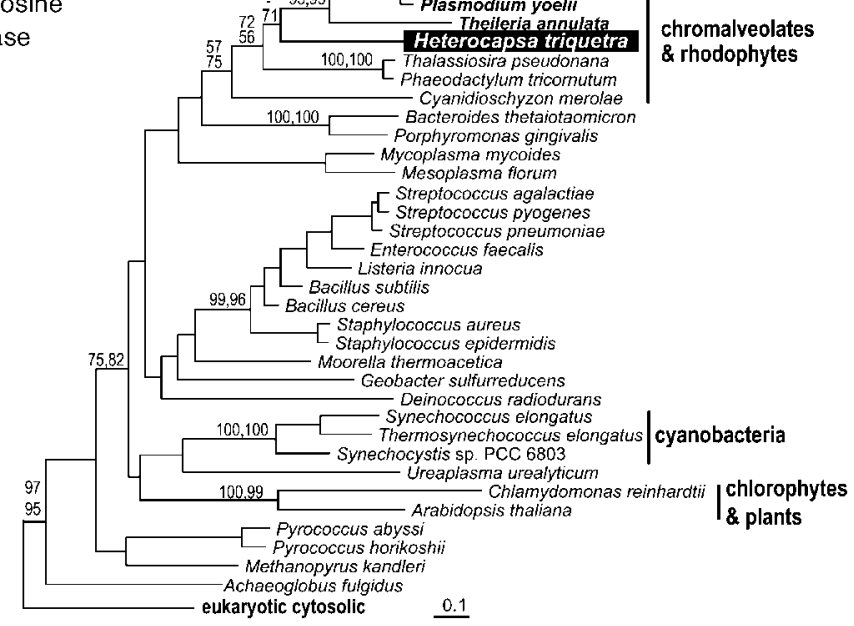

(c) 1-Deoxy-D- Stevia rebaudiana xylulose-5phosphate synthase

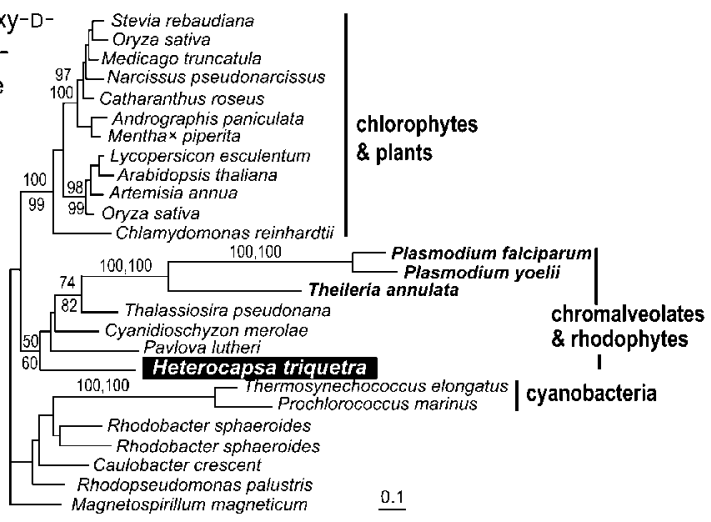

(b) Queuine tRNA ribosyl transferase
Salmonella typhimurium

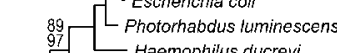

Photorhabdus tuminescens

Heemophilus ducreyi

- Maemophilus ducreyj

- Burkhoideria fungorum

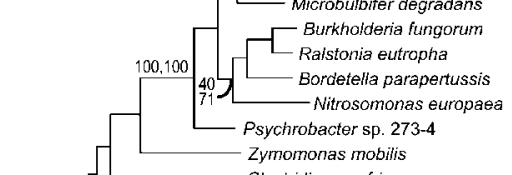

Zymomonas mobilis

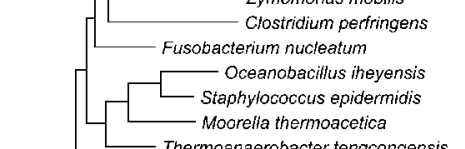

Mocrella thermoacetica
Thermoanaerobacter tengcongensis

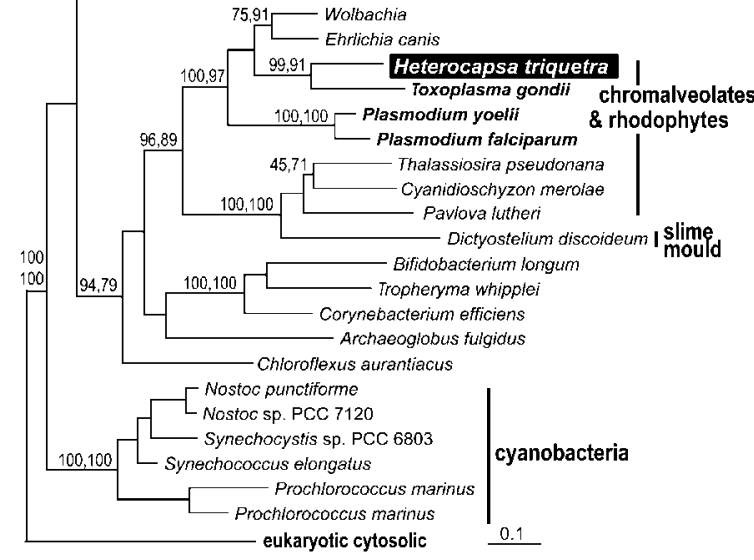

Fig. 2. Relationship between dinoflagellate and apicomplexan plastid-targeted proteins dimethyladenosine synthase (a), queuine tRNA ribosyltransferase (b) and 1-deoxy-D-xylulose-5-phosphate synthase (c). See the legend to Fig. 1 for other details.

algae, including red algae, or bacteria (Archibald et al., 2003). In dinoflagellates, RuBisCO has long been known to be of a bacterial type and considered to have originated by lateral gene transfer (Rowan et al., 1996; Whitney et al., 1995). One additional protein, $\delta$-aminolaevulinic acid dehydratase, has also been suggested to be derived from a green alga along with other more complex cases (Hackett et al., 2004a), but the extent to which dinoflagellate plastid proteins may not originate from a single source is not well known. Other than the well-studied RuBisCO, it is similarly unclear whether any bacterial proteins have been harnessed in the plastid.

In our survey, a handful of proteins branched with the green algae or plants rather than the red plastid clade, but in all cases except one this was without support (Table 1). The one exception, the oxoglutarate/malate translocator (Fig. 3a), is interesting because, to date, the only eukaryotic sources from which it has been reported are plastids of plants and green algae. Since the preponderance of genes support the red origin of the dinoflagellate plastid, the presence of this protein in $H$. triquetra but not in finished genomes of red algae or diatoms (Armbrust et al., 2004; Barbier et al., 2005; Matsuzaki et al., 2004) or in any other known red or red-derived plastids suggests that this dinoflagellate protein is derived by lateral gene transfer from a green source.

Even more interesting, the $H$. triquetra acetolactate synthase (Fig. 3b) appears to have originated from a non-plastid source. The protein is known to exist in cyanobacteria and other plastids, but the $H$. triquetra gene is related to neither and instead forms a highly supported group within alphaproteobacteria ( $100 \%$ support), specifically related to a Paracoccus/Rhodobacter subgroup (96-98\% support). Nested well within a group of related bacteria as this is, it suggests that this gene is derived relatively recently from an alphaproteobacterial genome. The gene was represented by 13 ESTs, which indicates that it is highly expressed, and we also discovered a related homologue in a subsequent EST 
(a) Oxoglutarate/malate translocator

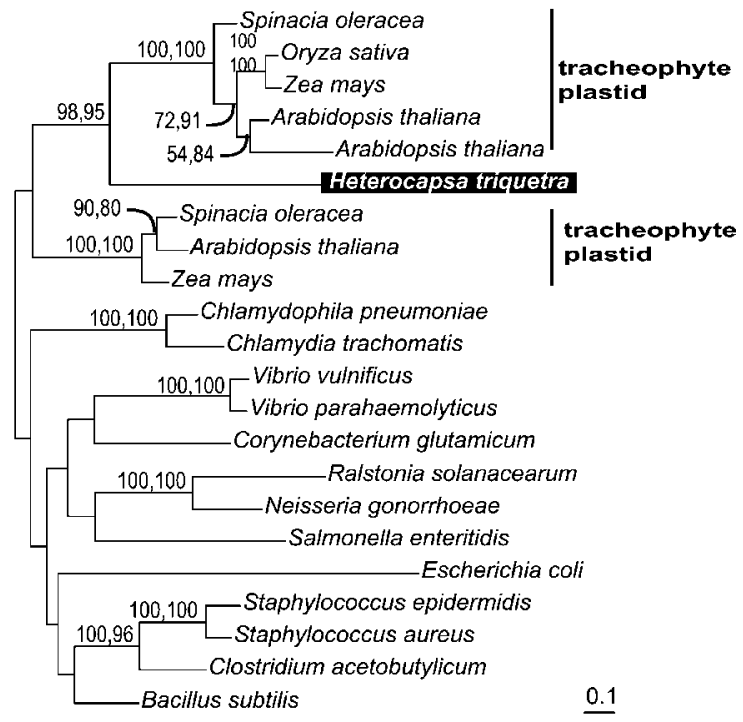

(b) Acetolactate synthase

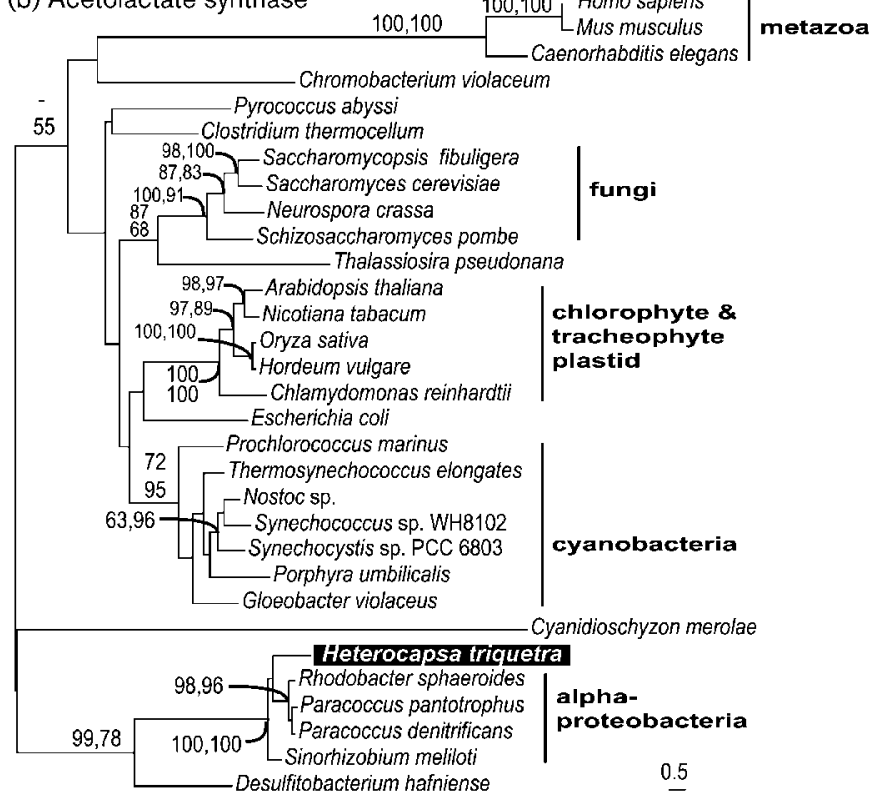

(c) Translation elongation factor Ts

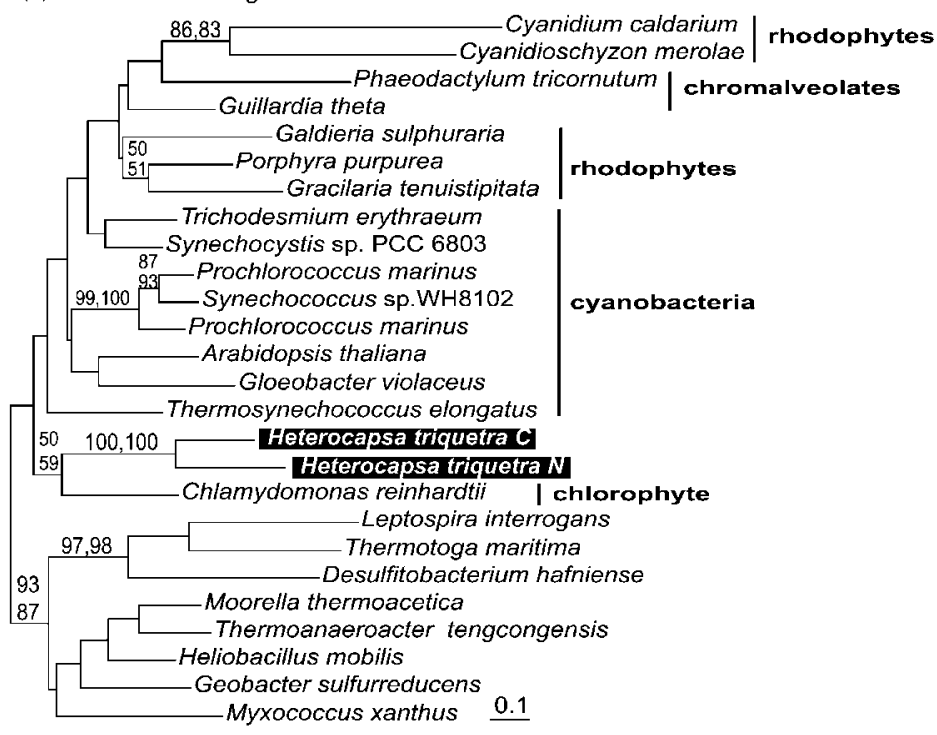

Fig. 3. Phylogenies of three dinoflagellate plastid-targeted proteins with unusual evolutionary histories. (a) The oxoglutarate/malate translocator is only known in green algal plastids and now also dinoflagellates. (b) The $H$. triquetra acetolactate synthase is closely related to those of alphaproteobacteria and is suggested to have originated by lateral gene transfer. (c) The H. triquetra EF-Ts is a unique tandem duplication where the two halves (labelled $\mathrm{C}$ and $\mathrm{N}$ ) are closely related, suggesting a recent duplication. See the legend to Fig. 1 for other details. survey of another species of dinoflagellate, Karlodinium micrum (Patron et al., 2006), both strongly supporting the conclusion that this gene is encoded in the dinoflagellate genome (as opposed to being a bacterial contaminant). It is not clear whether this gene is common to other chromalveolate plastids or indeed even whether all other dinoflagellates encode this gene, but its apparent recent origin suggests that its distribution may be relatively restricted in these plastids.

Lastly, one of the $H$. triquetra genes that branches weakly with the green algae is EF-Ts. The phylogeny of this gene (Fig. 3c) is too weak to conclude much about its origin; however, it is noteworthy because of its unique structure. The $H$. triquetra gene encodes a tandem duplication of
EF-Ts and the phylogeny shows that the two halves of the duplication branch together with $100 \%$ support. This close relationship between the two halves shows that the duplication took place relatively recently, which has interesting implications for the function of this protein, which recycles GDP from elongation factor-Tu during translation elongation. Several other dinoflagellate proteins are expressed as polymers, some of which are processed and some are functional fusion proteins (Hiller et al., 1995; Liu et al., 2004; Rowan et al., 1996). It is not clear whether the EF-Ts is processed or not. Despite this protein having a housekeeping role in translation, we could not identify a plastid version in apicomplexans, but we did find non-duplicated plastid homologues of EF-Ts in a diatom (Phaeodactylum) and a cryptomonad (Guillardia). The distribution of this 
character is relatively restricted, therefore, but seeking this protein in other apicomplexans might be of interest.

\section{Concluding remarks}

Overall, the phylogeny of dinoflagellate plastid-targeted proteins supports the origin of this organelle from the red plastid lineage. This is consistent with previous suggestions based on pigmentation (chlorophyll $c$ is found in dinoflagellates and chromists) and some molecular data, but the analyses described here provide more consistency than previously observed with molecular phylogenetic surveys. In general, dinoflagellate proteins also tend to branch with homologues from other chromalveolates, although no single protein shows this relationship unambiguously and the best evidence for this remains the unusual evolutionary histories of GAPDH and FBA. The few plastid proteins available from both dinoflagellates and apicomplexans tend to support a common origin of these two plastids and add further evidence for the red ancestry of apicomplexan plastids. Altogether there is very little evidence to support a green origin for either dinoflagellate or apicomplexan plastids. Confirming that the dinoflagellate plastid is related to those of apicomplexans and the chromalveolates as a whole is significant for several reasons, in particular because of the many differences between dinoflagellate and apicomplexan plastids. Distinctions in membrane number and protein targeting between dinoflagellates and other chromalveolates mean that dinoflagellates must have undergone a dramatic transformation necessitating changes to the targeting system and also to the transit peptides of perhaps hundreds of proteins (Nassoury et al., 2003; Patron et al., 2005). In addition, a plastid-containing ancestor of apicomplexans and dinoflagellates is interesting because deep-branching members of these two lineages, Colpodella and Perkinsus, respectively (Goggin \& Barker, 1993; Kuvardina et al., 2002), potentially enable us to reconstruct many characteristics of this ancestor and the subsequent evolution of both groups in detail (Leander \& Keeling, 2003).

Analyses of plastid-targeted protein genes also continue to show the evolutionary complexity of dinoflagellate plastids, and indeed plastids as a whole. There are now a handful of dinoflagellate plastid proteins that do not seem to fit with the overall picture of the plastid's evolution from the red plastid lineage: this work and other studies (Hackett et al., 2003) have shown some proteins being more akin to green homologues and others being only distantly related to plastid homologues in general. This is similar to observations from another myxotrophic alga, B. natans (Archibald et al., 2003), raising interesting questions about the genetic content of such genomes in general. In addition, dinoflagellates seem to be prone to developing novelty at the molecular level (Hackett et al., 2004b), as evident from their plastid proteins. Complexes appear to form between proteins from distantly related sources and new structures are found, making dinoflagellates an interesting case study of molecular diversity in microbial eukaryotes.

\section{ACKNOWLEDGEMENTS}

This work was supported by the Protist EST Program of Genome Canada/Genome Atlantic and by a grant (MOP-42517) from the Canadian Institutes for Health Research (CIHR). R. F. W. is supported by Fellowships from CIHR and the Michael Smith Foundation for Heath Research (MSFHR) and P. J. K. is a Fellow of the CIAR and a new investigator of the CIHR and MSFHR.

\section{REFERENCES}

Archibald, J. M. \& Keeling, P. J. (2002). Recycled plastids: a 'green movement' in eukaryotic evolution. Trends Genet 18, 577-584.

Archibald, J. M., Rogers, M. B., Toop, M., Ishida, K. \& Keeling, P. J. (2003). Lateral gene transfer and the evolution of plastid-targeted proteins in the secondary plastid-containing alga Bigelowiella natans. Proc Natl Acad Sci U S A 100, 7678-7683.

Armbrust, E. V., Berges, J. A., Bowler, C. \& 42 other authors (2004). The genome of the diatom Thalassiosira pseudonana: ecology, evolution, and metabolism. Science 306, 79-86.

Bachvaroff, T. R., Concepcion, G. T., Rogers, C. R., Herman, E. M. \& Delwiche, C. F. (2004). Dinoflagellate expressed sequence tags data indicate massive transfer of chloroplast genes to the nuclear genome. Protist 155, 65-78.

Baldauf, S. L., Roger, A. J., Wenk-Siefert, I. \& Doolittle, W. F. (2000). A kingdom-level phylogeny of eukaryotes based on combined protein data. Science 290, 972-977.

Barbier, G., Oesterhelt, C., Larson, M. D., Halgren, R. G., Wilkerson, C., Garavito, R. M., Benning, C. \& Weber, A. P. (2005). Comparative genomics of two closely related unicellular thermoacidophilic red algae, Galdieria sulphuraria and Cyanidioschyzon merolae, reveals the molecular basis of the metabolic flexibility of Galdieria sulphuraria and significant differences in carbohydrate metabolism of both algae. Plant Physiol 137, 460-474.

Blanchard, J. L. \& Hicks, J. S. (1999). The non-photosynthetic plastid in malarial parasites and other apicomplexans is derived from outside the green plastid lineage. J Eukaryot Microbiol 46, 367-375.

Bruno, W. J., Socci, N. D. \& Halpern, A. L. (2000). Weighted neighbor joining: a likelihood-based approach to distance-based phylogeny reconstruction. Mol Biol Evol 17, 189-197.

Cai, X., Fuller, A. L., McDougald, L. R. \& Zhu, G. (2003). Apicoplast genome of the coccidian Eimeria tenella. Gene 321, 39-46.

Cavalier-Smith, T. (1998). A revised six-kingdom system of life. Biol Rev Camb Philos Soc 73, 203-266.

Delwiche, C. F. (1999). Tracing the thread of plastid diversity through the tapestry of life. Am Nat 154 (Suppl. 4), S164-S177.

Fast, N. M., Kissinger, J. C., Roos, D. S. \& Keeling, P. J. (2001). Nuclear-encoded, plastid-targeted genes suggest a single common origin for apicomplexan and dinoflagellate plastids. Mol Biol Evol 18, 418-426.

Fast, N. M., Xue, L., Bingham, S. \& Keeling, P. J. (2002). Reexamining alveolate evolution using multiple protein molecular phylogenies. J Eukaryot Microbiol 49, 30-37.

Funes, S., Davidson, E., Reyes-Prieto, A., Magallón, S., Herion, P., King, M. P. \& Gonzalez-Halphen, D. (2002). A green algal apicoplast ancestor. Science 298, 2155.

Gajadhar, A. A., Marquardt, W. C., Hall, R., Gunderson, J., AriztiaCarmona, E. V. \& Sogin, M. L. (1991). Ribosomal RNA sequences of Sarcocystis muris, Theileria annulata and Crypthecodinium cohnii reveal evolutionary relationships among apicomplexans, dinoflagellates, and ciliates. Mol Biochem Parasitol 45, 147-154. 
Goggin, C. L. \& Barker, S. C. (1993). Phylogenetic position of the genus Perkinsus (Protista, Apicomplexa) based on small subunit ribosomal RNA. Mol Biochem Parasitol 60, 65-70.

Guindon, S. \& Gascuel, O. (2003). A simple, fast, and accurate algorithm to estimate large phylogenies by maximum likelihood. Syst Biol 52, 696-704.

Hackett, J. D., Maranda, L., Yoon, H. S. \& Bhattacharya, D. (2003). Phylogenetic evidence for the cryptophyte origin of the plastid of Dinophysis (Dinophysiales, Dinophyceae). J Phycol 39, 440-448.

Hackett, J. D., Yoon, H. S., Soares, M. B., Bonaldo, M. F., Casavant, T. L., Scheetz, T. E., Nosenko, T. \& Bhattacharya, D. (2004a). Migration of the plastid genome to the nucleus in a peridinin dinoflagellate. Curr Biol 14, 213-218.

Hackett, J. D., Anderson, D. M., Erdner, D. L. \& Bhattacharya, D. (2004b). Dinoflagellates: a remarkable evolutionary experiment. Am $J$ Bot 91, 1523-1534.

Harper, J. T. \& Keeling, P. J. (2003). Nucleus-encoded, plastid-targeted glyceraldehyde-3-phosphate dehydrogenase (GAPDH) indicates a single origin for chromalveolate plastids. Mol Biol Evol 20, 1730-1735.

Harper, J. T., Waanders, E. \& Keeling, P. J. (2005). On the monophyly of chromalveolates using a six-protein phylogeny of eukaryotes. Int J Syst Evol Microbiol 55, 487-496.

Hiller, R. G., Wrench, P. M. \& Sharples, F. P. (1995). The lightharvesting chlorophyll a-c-binding protein of dinoflagellates: a putative polyprotein. FEBS Lett 363, 175-178.

Ishida, K. \& Green, B. R. (2002). Second- and third-hand chloroplasts in dinoflagellates: phylogeny of oxygen-evolving enhancer 1 (PsbO) protein reveals replacement of a nuclear-encoded plastid gene by that of a haptophyte tertiary endosymbiont. Proc Natl Acad Sci U S A 99, 9294-9299.

Jomaa, H., Wiesner, J., Sanderbrand, S. \& 9 other authors (1999). Inhibitors of the nonmevalonate pathway of isoprenoid biosynthesis as antimalarial drugs. Science 285, 1573-1576.

Keeling, P. J. (2004). Diversity and evolutionary history of plastids and their hosts. Am J Bot 91, 1481-1493.

Köhler, S., Delwiche, C. F., Denny, P. W., Tilney, L. G., Webster, P., Wilson, R. J. M., Palmer, J. D. \& Roos, D. S. (1997). A plastid of probable green algal origin in apicomplexan parasites. Science 275, 1485-1489.

Kuvardina, O. N., Leander, B. S., Aleshin, V. V., Myl'nikov, A. P., Keeling, P. J. \& Simdyanov, T. G. (2002). The phylogeny of colpodellids (Alveolata) using small subunit rRNA gene sequences suggests they are the free-living sister group to apicomplexans. J Eukaryot Microbiol 49, 498-504.

Leander, B. S. \& Keeling, P. J. (2003). Morphostasis in alveolate evolution. Trends Ecol Evol 18, 395-402.

Liu, L., Wilson, T. \& Hastings, J. W. (2004). Molecular evolution of dinoflagellate luciferases, enzymes with three catalytic domains in a single polypeptide. Proc Natl Acad Sci U S A 101, 16555-16560.

Matsuzaki, M., Misumi, O., Shin-i, T. \& 38 other authors (2004). Genome sequence of the ultrasmall unicellular red alga Cyanidioschyzon merolae 10D. Nature 428, 653-657.

McFadden, G. I. (2001). Primary and secondary endosymbiosis and the origin of plastids. J Phycol 37, 951-959.

McFadden, G. I. \& Waller, R. F. (1997). Plastids in parasites of humans. Bioessays 19, 1033-1040.
Nassoury, N., Cappadocia, M. \& Morse, D. (2003). Plastid ultrastructure defines the protein import pathway in dinoflagellates. J Cell Sci 116, 2867-2874.

Patron, N. J., Rogers, M. B. \& Keeling, P. J. (2004). Gene replacement of fructose-1,6-bisphosphate aldolase supports the hypothesis of a single photosynthetic ancestor of chromalveolates. Eukaryot Cell 3, 1169-1175.

Patron, N. J., Waller, R. F., Archibald, J. M. \& Keeling, P. J. (2005). Complex protein targeting to dinoflagellate plastids. J Mol Biol 348, 1015-1024.

Patron, N. J., Waller, R. F. \& Keeling, P. J. (2006). A tertiary plastid uses genes from two endosymbionts. J Mol Biol 357, 1373-1382.

Ralph, S. A., van Dooren, G. G., Waller, R. F., Crawford, M. J., Fraunholz, M. J., Foth, B. J., Tonkin, C. J., Roos, D. S. \& McFadden, G. I. (2004). Tropical infectious diseases: metabolic maps and functions of the Plasmodium falciparum apicoplast. Nat Rev Microbiol 2, 203-216.

Rowan, R., Whitney, S. M., Fowler, A. \& Yellowlees, D. (1996). Rubisco in marine symbiotic dinoflagellates: form II enzymes in eukaryotic oxygenic phototrophs encoded by a nuclear multigene family. Plant Cell 8, 539-553.

Schmidt, H. A., Strimmer, K., Vingron, M. \& von Haeseler, A. (2002). TREE-PUZZLE: maximum likelihood phylogenetic analysis using quartets and parallel computing. Bioinformatics 18, 502-504.

Takishita, K., Patron, N. J., Ishida, K., Maruyama, T. \& Keeling, P. J. (2005). A transcriptional fusion of genes encoding glyceraldehyde-3phosphate dehydrogenase (GAPDH) and enolase in dinoflagellates. J Eukaryot Microbiol 52, 343-348.

Thompson, J. D., Gibson, T. J., Plewniak, F., Jeanmougin, F. \& Higgins, D. G. (1997). The CLUSTAL_X windows interface: flexible strategies for multiple sequence alignment aided by quality analysis tools. Nucleic Acids Res 25, 4876-4882.

Waller, R. F., Keeling, P. J., Donald, R. G. \& 7 other authors (1998). Nuclear-encoded proteins target to the plastid in Toxoplasma gondii and Plasmodium falciparum. Proc Natl Acad Sci U S A 95, 12352-12357.

Waller, R. F., Keeling, P. J., van Dooren, G. G. \& McFadden, G. I. (2003). Comment on "A green algal apicoplast ancestor". Science 301, 49.

Whitney, S. M., Shaw, D. C. \& Yellowlees, D. (1995). Evidence that some dinoflagellates contain a ribulose-1,5-bisphosphate carboxylase/oxygenase related to that of the alpha-proteobacteria. Proc Biol Sci 259, 271-275.

Wilson, I. R. J. M., Denny, P. W., Preiser, P. R. \& 8 other authors (1996). Complete gene map of the plastid-like DNA of the malaria parasite Plasmodium falciparum. J Mol Biol 261, 155-172.

Yoon, H. S., Hackett, J. D., Pinto, G. \& Bhattacharya, D. (2002). The single, ancient origin of chromist plastids. Proc Natl Acad Sci U S A 99, 15507-15512.

Yoon, H. S., Hackett, J. D., Ciniglia, C., Pinto, G. \& Bhattacharya, D. (2004). A molecular timeline for the origin of photosynthetic eukaryotes. Mol Biol Evol 21, 809-818.

Yoon, H. S., Hackett, J. D., Van Dolah, F. M., Nosenko, T., Lidie, K. L. \& Bhattacharya, D. (2005). Tertiary endosymbiosis driven genome evolution in dinoflagellate algae. Mol Biol Evol 22, 1299-1308.

Zhang, Z., Green, B. R. \& Cavalier-Smith, T. (1999). Single gene circles in dinoflagellate chloroplast genomes. Nature 400, 155-159.

Zhang, Z., Green, B. R. \& Cavalier-Smith, T. (2000). Phylogeny of ultrarapidly evolving dinoflagellate chloroplast genes: a possible common origin for sporozoan and dinoflagellate plastids. J Mol Evol 51, 26-40. 